\title{
PAISAGENS FESTIVAS E INTERAÇÕES MÍTICO- RITUALÍSTICAS EM PRÁTICAS TRADICIONAIS DO CATOLICISMO POPULAR
}

\section{- CARLOS EDUARDO SANTOS MAIA 1}

Resumo: A percepção mítica sobre a paisagem festiva é o tema desse artigo, no qual resgatamos as investigações de Ernst Cassirer sobre "a lógica do pensamento mítico". Iniciamos nossa abordagem procurando definir a paisagem como "aparição", o que lhe conferiria uma tonalidade afetiva. A seguir, discutimos como a paisagem nas festas populares, à maneira de aparição, põe em cena 0 fervor histórico, nos quais "estados embaraçados" são promovidos por apreensões mítico-ritualisticas da sua composição. Palavras-chave: Festa popular. Mito. Paisagem. Ritual.

\section{Antelóquio}

Em textos publicados pelo NEPEC/UERJ

(MAIA 2001a e 2010), procuramos expor como o espaço nas festas populares do catolicismo expressa categorias afetivas, às quais o geógrafo deve estar atento, que muitas vezes se contrapõem à lógica operacional universalizante que predomina nas análises científicas. Neste sentido, comentamos que "a emoção está na festa, ou melhor, no mundo festivo que, sobrecarregado afetivamente, encanta já e muito mais à medida que o migrante se desloca, fazendo do deslocar-se emocionado um ritual de passagem em sentido pleno (passagem de uma forma de apreender o mundo a outra)" (MAIA, 2001a, p. 184). Paralelamente, em Maia 2010, baseados em Sartre e Parkin, advertimos que as emoções ritualísticas promovem "estados embaraçados", posto que põem em cena determinada maneira de lidar com o mundo por meio de encantamento. No presente trabalho queremos, menos do que concluir, reabrir os caminhos nesta trilogia da geografia dos rituais em festas do catolicismo popular. Para tanto, trataremos da paisagem festiva. Nosso discurso 
resgata certas definições de paisagem que nos permitem aceder à questão proposta: a abordagem geográfica das interações mítico-ritualísticas em festas populares.

\section{Paisagem: da aparência à aparição}

Iniciemos tal discussão recuperando a distinção entre espaço e paisagem em Milton Santos, no seu já clássico trabalho $A$ Natureza do Espaço. Nesta obra, Santos afirma que "paisagem e espaço não são sinônimos. A paisagem é o conjunto de formas que, num dado momento, exprimem as heranças que representam as sucessivas relações localizadas entre homem e natureza. O espaço são essas formas mais a vida que as anima". O autor observa que "a rigor, a paisagem é apenas a porção da configuração territorial que é possível abarcar com a visão" (SANTOS, 1996, p. 83), demonstrando com isso que a postura "ocularista" em tratar da paisagem não é privilégio da tradição em pesquisa da geografia cultural (Cf. DUNCAN, 2004). Aqui, Santos recupera um princípio de definição da paisagem na geografia tributário do léxico estético e referenciado na superfície visual da imagem (CLAVAL, 2004). Logo a seguir, Santos distingue paisagem e espaço definindo este como "um sistema de valores" em "constante mudança", de qualquer modo é "tempo presente", e aquela como um "sistema material", ou seja, um "conjunto de objetos concretos transtemporais". Destarte, a paisagem nos informa sobre a presença de objetos técnicos do passado e do presente, já no espaço (re)produz-se a atribuição de uma função/dinamismo aos objetos técnicos no tempo presente. $\mathrm{O}$ autor não nega, assim, que a paisagem tenha uma função na sociedade atual, mas esta não portaria a mesma possibilidade estruturante que Santos (1996, Cf. SANTOS, 2008) confere ao espaço porque, nas suas palavras, "a paisagem é história congelada, mas participa da história viva. São suas formas que realizam, no espaço, as funções sociais" (SANTOS, 1996, p. 86).

Nesta leitura de Santos atrelada à razão, "sem 'emoção", valorizam-se determinadas dimensões da paisagem assinaladas por Corrêa e Rosendahl (1998) - principalmente as dimensões morfológica, funcional e fenomênica - negando-se a possibilidade de outras; pois, a seu ver, "considerada em si mesma, a paisagem é apenas uma abstração, apesar de sua concretude como coisa material" (SANTOS, 1996, p. 87). Este apreço em situar a paisagem no campo da razão e da técnica não é exclusivo de Santos, pois o notamos também em Cosgrove ao afirmar que paisagem, "ao contrário de meio ambiente e espaço, lembra-nos que apenas através da consciência e razão humanas este esquema é conhecido por nós, e apenas através da técnica podemos participar dela como seres humanos" (1998, p. 100). Mas que terrenos desbravaríamos se colocássemos a emoção como variável fundante na definição de paisagem e inseríssemos um "elemental", qual seja, o tempo presente como possibilidade de abertura à co-presença, ou, de outro modo, a paisagem como uma "convergência, um momento vivido"? E se isto nos conduzisse a possibilidades não somente técnico-científicas, 
mas também às afetivas, inicialmente mencionadas no trabalho, já que "a paisagem se unifica em torno de uma tonalidade afetiva dominante, perfeitamente válida embora refratária a qualquer redução meramente científica" (DARDEL, 1952, p. 41-42)?

Comecemos a explorar tais possibilidades a partir dos comentários do próprio Cosgrove (1998) de que cada paisagem oferece os "limites de comportamento" e os "códigos apropriados de conduta", tendo estes, a nosso ver, além de legitimidade e respaldo em relações de poder, implicações profundas a partir daquela "tonalidade afetiva dominante" que acabamos de citar, ainda que esta tonalidade afetiva seja moldada pelo tropo da "narrativa", tal como Duncan (2004) compreende este elemento de retórica das paisagens. Qualquer tonalidade afetiva nos coloca às margens da perspectiva ocularista e solicita que a paisagem seja "verdadeiramente geográfica por seus prolongamentos, como o espaço de fundo real ou imaginário que se abre para além do olhar (...). Não uma linha fixa, mas um movimento, um impulso" (DARDEL, 1952, p. 42). Nesse horizonte, "descongelamos" a paisagem e a temos não só como forma relacionada a uma herança, ou a um conjunto dado de objetos técnicos, mas fundamentalmente à maneira de aparição, e tudo que se mostra à maneira de aparição é carregado de afetividade.

Ao propormos que paisagem é originariamente aparição (e não "aparência") talvez não estejamos falando novidade alguma, pois Tuan, de certo modo, indica esse assunto, nas suas "paisagens do medo", observando que estas "são as quase infinitas manifestações das forças do caos, naturais e humanas. Sendo as forças que produzem caos onipresentes, as tentativas humanas para controlá-las também são onipresentes. De certa forma, toda construção humana - mental ou material - é um componente na paisagem do medo, porque existe para controlar o caos" (2005, p. 12).

O problema na abordagem de Tuan está no fato de restringir-se exatamente à alusão das paisagens do medo como referentes a "estados psicológicos e ao ambiente real", misturando suas intenções fenomenológicas com aquela "inveja da Física" que Massey (1999) nota em certos "geógrafos humanos", ainda que isto se dê de modo disfarçado, ou seja, publicamente negado. Com isso, o autor acaba tratando o medo e as paisagens como tensões para ordenar o caos experiencial a partir de atos conscientes, como nota-se no trecho citado a seguir:

(...) O ruído não é um problema no campo, a não ser que a pessoa viva perto de uma ruidosa cachoeira. De qualquer modo as pessoas tendem a aceitar a maioria dos ruídos da natureza (..) como tranquilizantes. $O$ ruído na cidade é outra coisa. Para os recém-chegados, a cacofonia 
urbana pode, inicialmente, ser a experiência mais desorientadora $e$ assustadora (...). Com o tempo a pessoa aprende a tolerar o ruído, que deixa de assustá-la. Porém, o ruído continua a criar tensão e ansiedade - passando a nos lembrar o caos. (TUAN, 2005, p. 234).

Tal enfoque torna-se problemático quando pensamos nos tiroteios que acontecem, às vezes, em determinadas áreas de cidades como o Rio de Janeiro. Será que aprendemos a tolerar o ruído dos tiros e estes não criam nada mais que tensão e ansiedade que nos lembram do caos? $\mathrm{Ou}$, por outro lado, não lidamos com isso mediante estruturas de atos conscientes, mas por uma emoção fundante que promove estados afetivos mais diversos que tensão e ansiedade, como por exemplo, um verdadeiro estado de choque paralisante, por mais que tenhamos "aprendido" a conviver com isso e vejamos ou leiamos sobre tiroteios acontecendo de modo recorrente?

Diríamos que a paisagem, à maneira de aparição, remete-nos, a princípio, a uma dimensão na qual se enfatiza que esta possui uma dimensão subjetiva; dimensão esta que pode ser melhor ainda situada em termos de horizonte compreensivo da espacialidade da paisagem como possibilidade de realização do "espaço intramundano" como Heidegger (1988 e 1990) o define, já que aí o ser-no-mundo, como pre-sença, introjeta o espaço. Desse modo, conforme propõe
Curado, "a paisagem demonstra o ser-no-mundo que a constituiu" (2006, p. 34).

Considerando o leque aberto a partir da definição de paisagem à maneira de aparição, pode-se falar de paisagens festivas, o que seria impróprio ou restrito se se concebe a paisagem como "história congelada". Para nós, a paisagem festiva é fundamentalmente fervor histórico (e geográfico), e não congelamento. Claval nos incita a pensar sobre o fervor nas paisagens festivas comentando que "as festas e as procissões são ocasiões de tornar manifesta a ordem frequentemente escondida da sociedade e de reconhecer os méritos dos grupos que são mantidos em posição subalterna, mas não são menos meritórios" (1996, p. 7). Embora seja importante atentarmos para esse contexto revelado nas paisagens festivas, não podemos nos esquecer de que, em sendo constituídas por tradições, outras relações aparecem, já que

$$
\begin{aligned}
& \text { "as tradições (...) também se } \\
& \text { realizam pela negociação interna } \\
& \text { que se desenvolve durante (...) } \\
& \text { uma festa. Assim sendo, não se } \\
& \text { tornam apenas instrumento de } \\
& \text { poder e domínio, mas (...) de } \\
& \text { consenso e decisão } \\
& \text { compartilhada (...). A cada } \\
& \text { repetição, a tradição é diferente } \\
& \text { do que foi anteriormente" } \\
& \text { (CURADO, 2006, p. 87). }
\end{aligned}
$$

Nós mesmos já advertimos sobre tal caráter da tradição festiva, ressaltando a necessidade de se contextualizá-la a partir de seu 
polo antitético, qual seja a ruptura (MAIA, 2001b). Todavia nosso interesse aqui são as paisagens festivas e as interações mítico-ritualísticas e, embora a tradição tenha muito a ver com isso na qualidade de modo de compreensão (TOMPSON, 1998; HEIDEGGER, 1988; MAIA，2001b), nos esquivamos de estabelecer maiores comentários sobre isto em função dos limites que nos indicaram para a produção deste texto. Voltemo-nos, assim, para o que nos interessa: as interações míticoritualísticas.

\section{O Espaço Mítico: Lucubrações de um Geógrafo}

Como exploramos a questão da espacialidade ritualística em Maia (2010), concentraremos nossos esforços aqui em abordar os mitos. Para tanto, recuperemos a assertiva de Cassirer de que "o mito parece ser, à primeira vista, um mero caos - massa informe de ideias incoerentes; e buscar as 'razões' destas ideias parece vã futilidade. Se algo existe que seja característico do mito é o fato de ser 'inexplicável" (1977, p. 121). Porém essa é apenas uma impressão apressada já que, de acordo com Cassirer (1977 e 2004), o pensamento mítico, ao contrário do que supõem determinadas leituras que se fizeram sobre ele, não é um estágio intelectual primitivo e "irracional". O filósofo propõe que tal pensamento é decorrente do contato imediato com a concretude do dado sensorial, aspecto igualmente observado por Rosendahl (1994 e 1999), mas ele complementa notando que este contato é impregnado de afetividade e emoção. De outro modo, o que diferencia a "lógica do pensamento mítico", a lógica da percepção e a lógica científica, num primeiro plano, é o grau de afetividade/emoção com que a experiência se realiza no mito. Assim, "não existe fenômeno natural nem da vida humana que não seja suscetível de uma interpretação mítica e que não reclame semelhante interpretação" (CASSIRER, 1977, p. 112-123).

Em seus estudos, Cassirer repara que há uma diversidade de ideias mitológicas que os cientistas tentaram unificar; intenção que, à primeira vista, pareceu impossível, mas a seguir tornou-se viável devido às recorrências de "pensamentos elementares" em diferentes culturas. Para Cassirer, ainda que tenham certa validade, as explicações científicas sobre o mito, isto é, uma teoria do mito é altamente desafiadora, pois este, "em seu verdadeiro sentido e essência, não é teórico. Sua lógica - se tiver alguma - é incomensurável com todas as nossas concepções de verdade empírica ou científica". Cassirer, entretanto, aceita este desafio de buscar um "'sentido' filosófico" no mito, descartando o seu alcance pelo método tradicional, estabelecido desde os estoicos, que acabava por negar mesmo os mitos, encarando este mundo como "artificial, um pretexto para outra coisa qualquer; em lugar de ser uma crença é um simples faz-de-conta". Também refuta a racionalidade científica vigente à época de seus escritos, segundo a qual os mitos não eram mais tidos "como mera invenção feita com um propósito especial", mas enquanto ficções inconscientes. Tais estudos redundaram numa proposta objetiva, de "classificar os objetos do pensamento mítico", e outra subjetiva, que 
realizava "o mesmo com seus motivos". Neste contexto, observa Cassirer, "se, ao cabo de tudo, conseguir descobrir um único objeto ou um simples motivo, que contenha e compreenda todos os outros, terá atingido seu objetivo e cumprido sua tarefa". Logo, Cassirer rechaça veementemente a busca por objetos telúricos ou astronômicos que expliquem os mitos, tanto quanto a (psic)análise freudiana que deseja "compreender o mundo mítico por um processo de redução intelectual", redundando em exageros (1977, p. 123-125).

Cassirer começa a expor seu método de explorar o mito estabelecendo correlações deste com a criação artística, com a qual se aproxima especialmente a poesia. Cabe, neste momento, a menção de Heidegger de que "é a poesia que, inicialmente, faz da habitação uma habitação. A poesia é o verdadeiro 'fazer habitar' (...) E como fazer habitar, a poesia é um 'bâtir'" (1958, p. 127) no sentido de cultivar. Para Heidegger, o fundamento da existência do homem situa-se no modo de erguer a morada humana num espaço de inter-relação em que a poesia é o modo de fazer ver o sentido do mundo, não sendo esta apenas uma expressão da alma como divertimento ou ornamento da existência. A poesia revela a verdade do ser. Aventamos aqui que mito e poesia se aproximam no sentido em que ambos são modos de cultivar um espaço no sentido heideggeriano, ou seja, de habitar como desvelamento do que cada um é. Porém, mito e arte se aproximam ao mesmo tempo em que se diferenciam, já que no mito o ato de crença na realidade do objeto é fundante, diferente do que ocorre na "lógica poética", desdobramento do que ele menciona como "a mais inocente de todas as ocupações", sem comprometimentos com ideologias, ou com a própria "lógica".

Por outro lado, se comparamos mito e ciência, somos conduzidos de imediato à conclusão de que ambos, por caminhos distintos, buscam a "realidade", ou a "unidade do mundo" (CASSIRER, 1977 e 2004). Todavia, para Cassirer, a definição do mito como uma razão apenas "etiológica" não é satisfatória. Neste sentido, afirma que "não podemos reduzir o mito a certos elementos estáticos fixos, mas procurar apreendêlo em sua vida interior, em sua mobilidade e versatilidade, em seu princípio dinâmico". A seu ver, para apreender esta vida interior do mito há que se relevar o problema sob "um ângulo diferente. $\mathrm{O}$ mito, por assim dizer, tem duas caras: de um lado, mostra-nos uma estrutura conceitual; de outro, uma estrutura perceptual. Não é uma simples massa de ideias desorganizadas e confusas; depende de um modo definido de percepção" (1977, p.127). Para o autor, o mito parte de uma percepção diferente do mundo e é isto que se deve investigar inicialmente quando se tem em conta a "lógica do pensamento mítico".

Cassirer investe sobre tal característica do mito levando em conta que o pensamento empírico é fundamentalmente operacional e causal, buscando "uma distinção entre o que é substancial ou acidental, necessário ou contingente, invariável ou transitório"; com isso, produz-se analiticamente o mundo dos objetos físicos com "propriedades fixas e determinadas" (1977, p.127). Já o que ocorre no pensamento mítico são percepções de ESPAÇO E CULTURA, UERJ, RJ, N. 30, P.19-35, JUL./DEZ. DE 2011 
caracteres fisiognômicos de um mundo dramático, e não objetivo e operado por leis. Neste ponto, Cassirer nos introduz na discussão de determinada característica do pensamento mítico que procuramos relevar quando tratamos dos rituais: a emoção. Acerca disso, o autor argumenta:

$$
\begin{aligned}
& \text { A percepção mítica está sempre } \\
& \text { impregnada destas qualidades } \\
& \text { emocionais: o que se vê ou se } \\
& \text { sente é cercado de uma } \\
& \text { atmosfera especial - de alegria } \\
& \text { ou tristeza, angústia, excitação, } \\
& \text { exultação ou depressão. E não } \\
& \text { podemos falar de 'coisas' como } \\
& \text { matéria morta ou indiferente. } \\
& \text { Todos os objetos são benignos } \\
& \text { ou malignos, amigos ou } \\
& \text { inimigos, familiares ou } \\
& \text { sobrenaturais, encantadores e } \\
& \text { fascinantes ou repelentes e } \\
& \text { ameaçadores. (CASSIRER, } \\
& \text { 1977, p.128). }
\end{aligned}
$$

Partindo desta concepção da "lógica do pensamento mítico" cabem as seguintes indagações: nas práticas ritualísticas do catolicismo popular, durante as festas, o homem não se relacionaria com Deus e santos (as) mais na qualidade de mitos que podem ser piedosos ou inclementes, próximos-familiares ou inacessíveis, benfeitores ou ameaçadores? Isto não estaria traduzido nos rituais de passagem, nos quais, como mencionamos em Maia (2010), os direcionamentos e posicionamentos espaciais são mais importantes do que as palavras? Esses rituais, tanto quanto satisfazem os seguidores da postura ocularista que analisam os objetos e suas funções, já que deixam sensíveis marcas na paisagem (portais, velas acessas, ex-votos, cores, comidas e bebidas próprias com seus resíduos, sons, cheiros, texturas, etc.), não nos revelam, paralelamente, outra "lógica" de lidar com o espaço, constituindo uma paisagem pela emoção dos rituais e mitos?

Retornando a Cassirer, o autor faz a seguinte advertência: "se quisermos explicar o mundo da percepção e da imaginação mítica não devemos começar com uma crítica de ambas do ponto de vista de nossos ideais teóricos de conhecimento e verdade, mas acolher as qualidades da experiência mítica em seu 'imediato

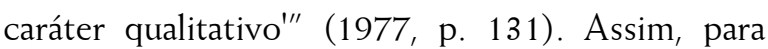
ele, não há que se procurar no mito uma sistematização semelhante àquela encontrada em outros tipos de conhecimento e complementa notando que "o mito não é um sistema de credos dogmáticos. Consiste, muito mais, em ações do que em meras imagens e representações" (1977, p. 131); ou ainda, "o mito aspira uma hierarquia de forças e divindades" (2004, p. 119). Desse modo, os mitos não podem ser confundidos apenas com um repertório de crenças depositadas na memória popular, posto que são expressões concretas de sentimentos e emoções traduzidas em ações.

Ao longo de seu trabalho investigativo, Cassirer concorda com a escola sociológica francesa de Durkheim e seguidores, na qual o pensamento mítico possui um caráter fundamentalmente social, mas discorda quando a escola durkheimiana atribui a este pensamento um caráter "pré-lógico ou místico", pois, a seu ver, as 
interpretações míticas, assim como as religiosas, não são desprovidas de racionalidade e, neste momento, ele previne que "o que nós, do nosso ponto de vista, podemos denominar irracionais, pré-lógicas, místicas, são as premissas com que se inicia nossa interpretação mítica ou religiosa, mas não o modo de interpretação" (1977, p. 133). Segundo Cassirer, as interpretações da tradição de pesquisa sobre os mitos falharam, pois "ignoraram os fatos fundamentais da experiência mítica. O verdadeiro substrato do mito não é de pensamento, mas de sentimento"; ou seja, o mito não antilógico, místico, confuso ou ilógico, "mas sua unidade depende muito mais da unidade de sentimento que de regras lógicas". Desse modo, o pensamento mítico porta uma "visão da vida sintética e não analítica (...). Os limites entre as diferentes esferas não são barreiras intransponíveis, mas fluentes e flutuantes (...). Nada possui forma definida, invariável, estática: por súbita metamorfose qualquer coisa pode transformar-se em qualquer coisa" (1977, p. 134). Se em Maia 2010 dissemos que os rituais nas festividades promovem estados embaraçados, aqui vemos que nos mitos, enquanto ação e hierarquia de forças, isto também é dado como possibilidade, diferente do que ocorre quando estes são tomados apenas como "crença" ou tradição oral que confirmam a distinção da Igreja entre domínios sagrados e profanos. Esse estado embaraçado se verifica mesmo na paisagem com a confluência de rituais diversos em que se interagem com os mitos prestando-lhes homenagem dentro de um sistema hierárquico (devoto-santo), seja na igreja, seja nas barraquinhas, seja nas patuscadas, ou nos folguedos.

Note-se, porém, que o pensamento mítico não parte de uma divisão do mundo entre esferas práticas e teóricas, mas "é fruto da emoção e seu cenário emocional imprime, em todas as suas produções, sua cor específica" (CASSIRER, 1977, p. 135-136), enquanto estabelece determinado modo de se conceber a unidade na multiplicidade não por razões causais, mas por uma visão simpática. Destarte,

"o mundo mítico é 'concreto' não porque tem a ver somente com conteúdos sensívelobjetivos, nem porque exclui de si e rejeita todos os momentos meramente 'abstratos', tudo o que é unicamente significação e signo; mas sim porque nele os dois momentos, o momentocoisa e o momento-significação, se dissolvem sem distinção, porque cresceram juntos, 'concresceram' em uma unidade imediata" (CASSIRER, 2004, p. 53).

Por isso, qualquer modificação na paisagem festiva costuma provocar contendas e desavenças, pois está em jogo a relação estabelecida com o mito, bem como a eficácia do ritual, pois nela os momento-coisa e momentosignificação estão absolutamente fundidos, estruturando o espaço-tempo presente. 
Acerca da relação entre mito e religião, Cassirer profere: "em todo o curso de sua história, a religião permanece indissoluvelmente ligada a elementos míticos e repassada deles. Por outro lado, até em suas formas mais grosseiras e rudimentares, o mito contém motivos que, em certo sentido, antecipam os ideais religiosos mais elevados" (1977, p. 143). No catolicismo popular talvez prevaleçam mesmo referências "míticas" sobre as "doutrinas", rituais (estados embaraçados) sobre ritos em sentido estrito (regras), emoção/ação sobre a razão/"crença". Por isso, o devoto no catolicismo popular não pode ser visto como um mero temente a Deus ou aos Santos (as), estabelecendo com ele uma relação passiva de medo ou prostração, pois, como aprecia Cassirer, "de uma atitude inteiramente passiva não pode surgir nenhuma energia criadora" (1977, p. 149). A concepção do devoto apenas temente não se adequa particularmente aqui, em que trabalhamos a paisagem festiva à maneira de aparição em que se manifestam energias criadoras. A nosso ver, o devoto, nos rituais de homenagem aos santos, cultua as santidades e seus poderes, paradoxalmente demonstrando seu poder, como devoto, de gerenciar/negociar o que almeja. Desse modo, colocam-se imagens de santos de "cabeça para baixo", encobrem-se estas mesmas imagens, em alguns casos, com panos; noutros são oferecidas ou negadas determinadas "regalias" ou realizam-se "sacrifícios". Embora tudo isso possa ser tido como ato de "crença" ou prostração - e ilógico - expressa, mais fundamentalmente, cuidado e confiança do homem em gerenciar/negociar as possibilidades de potência desses santos e, por isso, a paisagem festiva à maneira de aparição ganha elementos próprios (velas, fogueiras, enfeites, rituais), quer dizer, mais como expressão de gerenciamento do que de submissão. Mas o homem, embora apanhado por este poder de gerenciamento da potência dos santos durante a festividade, deve mostrar-se como devoto, o que a princípio não se contrapõe à ideia de que este faz valer sua energia criadora, pois devoto significa etimologicamente dedicado e sujeito a encantamentos, encantamentos estes que, a nosso ver, originariam a própria transformação mágica do mundo festivo (MAIA, 2001a).

Em se tratando especificamente dos rituais de promessa, este gerenciamento/negociação torna-se interessante, pois, para o devoto, a prática da promessa é comumente vista como a busca do bem. Tem-se então que uma imagem, como "particularidade substanciada", é dotada de forças reais, não que a imagem seja confundida com o santo, mas torna-se, seu alter ego, seu ser "concreto-plástico" (Cf. CASSIRER, 1977 e 2004). Manipular a imagem é, assim, manipular a potência do santo e sua capacidade de fazer justiça; pois, no pensamento mítico, em todo signo "está a coisa como uma parte de si mesma" (2004, p. 128). A penetração da lógica religiosa, "do alcance da justiça", na lógica mítica, "da intensidade emocional", gerou rituais que inclusive foram vistos antanho como avessos aos dogmas e à própria crença, como nota-se na seguinte passagem:

\section{(...) Barro Preto, insignificante arraial, só era conhecido pelos}


muitos milagres que a simplicidade do povo, atribuía não a Deus, e sim pura e materialmente àquele grupo de pequenas imagens, e até que eu lá instalasse os Padres Redentoristas, não passava de um lugar onde por doze dias acudiam negociantes de todo o Estado de Goyaz, boiadeiros, mascates, mulheres de má vida, circos de cavalinhos e milhares de superstições, devotos que lá iam pagar as suas promessas, não poucas vezes feitas para obterem de Deus cousas contra a moral Cristã: vinganças separações de casais, adulterios etc.

Em sinal de agradecimento fazem longas jornadas, às vezes a pé, e lá vão para dependurarem nas paredes da igreja quadros representando ao vivo os milagres feitos, facas, pistolas, e membros do corpo feitos de cera virgem, até mesmo os genitais.

Há quem prometa exibir ao público as partes do corpo, até mesmo as pudendas, em que tiveram qualquer doença, e essa exibição, que chama logo a atenção dos romeiros, chamam um milagre. (SILVA, 2007, p. 165).

Tratemos agora da relação mitoespaço de modo mais específico. Comecemos a abordar isto a partir da observação de Cassirer de que a sensação que temos de algo se insere, desde sua primeira percepção, "em uma relação com as formas de espaço e tempo", configurando as possibilidades do "simultâneo" e do "sucessivo" (CASSIRER, 2001, p. 207) enquanto modos de ordenação da experiência. Na ciência, tais modos de ordenação são submetidos a um movimento lógico de objetivação, em que se busca subordinar o caos sensorial a leis universais. Desse modo, tempo e espaço na ciência tornam-se sistemas de relações que possibilitam a apreensão da realidade mediante leis gerais. Já no pensamento mítico, adverte Cassirer, "o espaço (...) ocupa uma posição intermediária singular, entre o espaço sensível da percepção e o espaço do conhecimento puro" (2004, p. 151). O espaço do conhecimento puro seria geral, posto que construído a partir de determinações das quais decorre o conceito de infinito. Por outro lado, na percepção não há o infinito, pois se prende aos "limites da capacidade humana de percepção" (2004, p. 152). Outra característica do espaço do conhecimento puro seria a homogeneidade, em que os pontos são determinações de situações, sendo o espaço, em seu ser, meramente funcional, e não substancial, como se pensou na planície isotrópica mencionada por CORREA (1995). A homogeneidade refere-se ao caráter mesmo do espaço como construto e, por este princípio, "a partir de cada ponto do 
espaço, podem ser realizadas as mesmas construções em todos os lugares e em todas as direções" (CASSIRER, 2004, p. 152). Por outro lado, no espaço da percepção, "cada lugar tem sua espécie e seu valor próprios" (CASSIRER, 2004, p. 153). Assim, enquanto o espaço do conhecimento puro é isotrópico, o espaço da percepção é anisotrópico, possuindo sistemas próprios de organização. Outra característica do espaço geométrico, além da infinitude e da homogeneidade ou do conhecimento puro seria a continuidade, já que desconhece ou ignora a diversidade.

Partindo dessas três características do espaço geométrico, concordamos com a afirmação de Cassirer de que o espaço mítico estaria mais próximo ao espaço da percepção do que aquele (geométrico); ou, nas suas palavras, "o espaço mítico, bem como o espaço da percepção, são produções da consciência inteiramente concretas" (2004, p. 153), havendo uma relação ontológica entre o que uma coisa é e o lugar que ocupa. No mito e na percepção, posição e conteúdo estão, diferentemente do que ocorre no espaço geométrico, intimamente relacionados, sendo toda posição preenchida por um conteúdo próprio e específico, sensível e vivido, sendo isto também característica básica dos rituais numa análise geográfica (MAIA, 2010). Por isso, todo aqui e lá, nota o autor, possui uma "tonalidade" própria, que diríamos ser afetiva, o que já não ocorre no espaço determinado por abstrações com vistas à universalidade. Neste aspecto cabe-nos considerar que a paisagem à maneira de aparição, enquanto composição de aqui e lá preenchidos por uma tonalidade afetiva, implica "algo" que se mostra e escapa, nunca deixando-se apreender de modo completo. Nas festas, particularmente, aqui e lá são espacialmente (re)constituídos por relações ritualísticas, que imprimem-lhes disposições próprias, conformando conteúdos e lugares. Assim, os giros de folias de reis compõem a paisagem festiva na concepção aqui proposta com certos interditos posicionais, tais como: devem sair pela direita e retornar pela esquerda, não podem estabelecer uma trajetória cruzada, mas sim girar, como diz o termo. Tais interditos posicionais relacionam-se com os significados afetivos dos lugares que se manifestam em tabus, já que a não observância disso pode conduzir à morte do festeiro ou de um folião, por exemplo. Desse modo, como esclarece Cassirer, "a cada uma dessas diversas direções estão vinculados, em certa medida, específicos valores afetivos míticos" (2004, p. 154), consagrando-se, no exemplo dado, temporariamente, posições de introjeção na paisagem que só têm sentido mesmo na festa. Nas congadas de Catalão, uma humanização específica do espaço pelos rituais também manifesta na paisagem festiva é demonstrada por Costa (2010). Nesse caso, tem-se o interdito dos ternos em passarem nas encruzilhadas de frente, ratificando numa festa católica um lugar sagrado para religiões de matrizes africanas. Ambas as situações confirmam os estados embaraçados de que temos falado amiúde, tanto quanto os atributos qualitativos diversos que o espaço tem no pensamento mítico, diferente da tentativa de homogeneização que ocorre no espaço geométrico. Acerca desta relação entre os 
atributos qualitativos e espaciais no pensamento mítico, Cassirer (2004, p. 155) comenta:

Toda diferença qualitativa
possui aqui, em certa medida,
um aspecto segundo o qual ela
aparece igualmente como
espacial, assim como toda
diferença espacial é e permanece
também uma diferença
qualitativa. Entre os dois
domínios ocorre uma espécie de
permuta, uma constante
passagem de um para o outro.

Cassirer (2004) continua observando que no espaço mítico as relações são estruturais, em que o todo não surge a partir de regras determinadas, mas por inerência e interioridade com as partes. Com isso, o cosmos pode se apresentar numa escala aumentada ou reduzida. Em todo caso, há uma igualdade originária de essência entre o todo e as partes. O filósofo denomina a isto de "lei da nivelação" e exara: "A parte não representa meramente o todo, nem o indivíduo ou a espécie representam o gênero, mas são ambas as coisas; não só implicam este duplo aspecto para a reflexão mediata, como compreendem a força imediata do todo, sua significação e sua eficácia" (2009, p. 109). Desse modo, a título de exemplo, comenta Cassirer (2004), a vida de uma pessoa, individualmente, pode ser "lida" no movimento e posição dos astros pela astrologia, estando toda intuição de forma fundida na intuição de conteúdo. Paralelamente, diríamos também que em toda paisagem festiva à maneira de aparição o sagrado manifesta-se no espaço dos rituais do catolicismo popular implicando igualmente fusão de forma e conteúdo, e não em separações derivadas da "crença"; pois na relação de negociação/gerenciamento já se estabelece antecipadamente onde-se-deve-fazer-oque-para-se-alcançar-algo, estando o lugar em que se faz o ritual intimamente implicado com a possibilidade de ser agraciado/justiçado/recompensado (princípio que se verifica igualmente em rituais de umbanda e candomblé). Destarte, para o devoto, não é melhor rezar com piedade em sua casa e acender uma vela ali mesmo para o santo, ou ir para a igreja de modo confortável no seu automóvel sem "sacrificar-se". Ao invés disso, tem que ir a pé, ou em carro-deboi, sozinho ou acompanhado, rezando ou "farreando", mas, fundamentalmente, com direcionamentos e posicionamentos espaciais ritualizados, pois isto implica a relação de forma e conteúdo espacial do pagamento da promessa e da sua capacidade de gerenciamento da relação com o santo, podendo-se comprometer severamente o resultado do negócio.

Para Cassirer, no pensamento mítico, como temos destacado, "entre aquilo que uma coisa 'é' e o lugar em que ela se encontra, nunca há uma relação meramente 'externa' e contingente; o próprio lugar é parte de seu ser, lugar ao qual se mostra preso por obrigações bem determinadas" (2004, p. 166). Na composição do lugar não se pode desprezar, no pensamento mítico, o valor dado ao posicionamento e ao direcionamento, o que implica a predeterminação de orientações a serem seguidas. Nas folias de Reis goianienses, por 
exemplo, a saída obrigatória pelo lado direito da casa significa a busca da direção nascente. Mas, se o lado direito de uma casa volta-se para o poente ou outra direção, a folia "desce a rua", faz "um giro", e toma a direção certa. O que está em jogo nisso não é só a "orientação do giro", mas também como a paisagem é apreendida à maneira de aparição neste mundo festivo enquanto estruturante de orientações e direções certas a serem introjetadas já que "o pensamento mítico apreende uma estrutura inteiramente determinada, concreta e espacial, a fim de, a partir dela, levar a termo o conjunto da 'orientação' do mundo" (2004, p. 167). Neste aspecto, o pensamento mítico assemelha-se às práticas ritualísticas, ou melhor, realiza-se mormente por estas, em virtude de que este, tal como nos rituais, parte de uma "qualificação" e "particularização" espacial (Cf. CASSIRER, 1977, 2001 e 2004), ou, segundo Cassirer, tende a "metamorfosear em diferenças espaciais todas as diferenças que põe e que apreende, e de torná-las imediatamente presentes para si nessa forma" (2004, p. 169).

Cassirer chama atenção para o fato de que a existência de direções diferenciadas é um dado da própria percepção. Desse modo, o que interessa investigar no pensamento mítico é a maneira como diferentes regiões são "realçadas" exatamente pela qualificação e particularização que assumem, não sendo estas, ao contrário do que ocorre no pensamento lógico científico ou na percepção, "meramente geométricas ou meramente geográficas, apenas idealmente pensadas ou apenas empiricamente percebidas; mas todo pensamento, assim como toda intuição e percepção sensíveis, se baseiam num fundamento afetivo originário" (2004, p. 171). Logo, as diferenças espaciais no pensamento mítico não são operadas pelo intelecto ou pelo seu puro aparecer, mas pela afetividade, pela ênfase de significação na medida em que se atribuem às direções e orientações valorações múltiplas e próprias, não sendo aí possível o espaço isotrópico, como temos dito.

Nesse ponto o autor comenta que a valoração do espaço é "um ato espontâneo da consciência mítico-religiosa; mas considerada objetivamente, ela está ligada a um determinado fato físico fundamental. $\mathrm{O}$ desdobramento do sentimento mítico de espaço parte sempre da oposição entre dia e noite, luz e escuridão" (2004, p. 172). Assim, alguns rituais de folias se distinguem em sua realização no espaço iluminado ou escurecido, já que os dias e as noites indicam não apenas tempos, mas os lugares próprios a cada giro; sejam de Santos Reis, do Divino Pai Eterno ou do Divino Espírito Santo, folias mais recorrentes em Goiás. Tomemos aqui duas dessas folias: as do Espírito Santo e a de Reis. As folias do Espírito Santo são famosas em Pirenópolis (GO), tanto as da roça como as da cidade, girando durante o dia e pousando à noite. Estas compõem uma paisagem festiva nos pousos com rituais de entrada e saída na passagem do "portal", cânticos, agradecimentos, rezas, comida, melhor dizendo muita comida, foguetório, dança e música, estes dois últimos aspectos principalmente nas folias não controladas pelo padre, já que "na roça" há atualmente duas folias: uma organizada pelo padre e outra organizada por um guardião da tradição local. É grande a concorrência de público nos giros 
de folia da roça e da cidade, notando-se descontrole da Igreja sobre a mesma. Daí a sua investida na organização de uma folia própria. Quando pesquisamos essas folias, principalmente as da roça, verificamos que uma grande parte dos foliões faz das mesmas um ritual de pagamento de promessa ao Divino Espírito Santo, miticamente enredado numa relação de negociação com o folião, que, por outro lado, se compromete a cumprir a observância dos rituais relativos à folia para demonstrar devoção. Essas "folias do Divino", conforme são popularmente conhecidas, costumam provocar mais conflitos com a Igreja do que as de Reis justamente em virtude dos pousos noturnos e do caráter "profano" que a Igreja atribui à festa - o que de modo algum corresponde à perspectiva tomada pelo devoto para com o Divino Espírito Santo acerca do gerenciamento de como a promessa deve ser paga. Se observarmos por outro lado as folias de Reis goianienses, seus giros são noturnos e o recolhimento diurno, pois o tempo-espaço de celebrar Deus Menino e a trajetória espacial dos Reis na paisagem em busca da Estrela Guia é distinto daquele da celebração à Pessoa do Espírito Santo.

Esta dessemelhança assinalada por Cassirer é também fundamental para entendermos dois rituais festivos: as fogueiras e as alvoradas. No ciclo junino, particularmente, as fogueiras são bastante comuns nas festas. A lenda sobre estas nos diz que, na noite do nascimento de João Batista, Isabel, prima de Maria, acendeu uma fogueira para avisar à sua prima a novidade. Já os rojões serviriam para "despertar" São João para o seu aniversário, espantando, paralelamente, os maus espíritos. Só que no livro de Lucas, que menciona Isabel, prima de Maria, não há nada sobre fogueiras ou rojões, o que nos leva a situar isso como mais uma das interpretações que a Igreja forneceu a rituais "pagãos" de modo a incorporarlhes nos cultos externos. Não vamos aqui discutir a origem desses rituais, mas o que queremos propor é uma interpretação do seu sentido, considerando que a fogueira e os fogos são luzes que irrompem à noite, aumentando o tempo da iluminação: a iluminação da festividade, da paisagem visível e invisível, das diferenças espaciais. Como a fogueira ilumina a festividade, a paisagem e a diferença espacial, cada fogueira já é em si mesma espacialmente diferenciada: a de Santo Antônio é quadrangular; a de São Pedro, triangular e a de São João, arredondada, demarcando a paisagem festiva relacionada a cada santo. Manifestam-se ainda na paisagem à maneira de aparição certos rituais celebradores do dia destes santos bastante notórios no catolicismo popular, tais como o levantamento de mastros, os enfeites, as comidas, as bebidas, as rezas de terços, a dança de quadrilha etc.

É interessante notar que a celebração ocorre à noite para comemorar o dia do santo - e não há nada mais significativo, portanto, do que encurtar a noite acendendo fogueiras e com foguetório de alvorada; ainda mais que, dado nosso posicionamento no hemisfério sul, nesta época, mês de junho, estamos passando pelo solstício de inverno. Apenas como contraponto, cabe mencionar a tradição em determinadas áreas do hemisfério norte, particularmente no baixo Mississipi, de se fazerem fogueiras de Natal, aqui 
inexistentes, já que estamos em pleno solstício de verão.

Retornando a Goiás, verificamos que na festa de Nossa Senhora da Penha, realizada em Corumbá de Goiás, no mês de setembro, época próxima ao equinócio de primavera, embora haja alvoradas, anúncio do dia, não há fogueiras, extensão da noite. Considerando-se a paisagem como aparência teremos uma explicação imediata para isto: as fogueiras são feitas em festas juninas. Porém, como aqui propomos situar a paisagem à maneira de aparição, não podemos relegar a inserção desta festa nas proximidades do equinócio de primavera que, no cerrado, é seguido por seca e incêndios, tendo o fogo outro significado neste espaço concreto de luz do equinocial.

\section{Considerações finais}

Como dissemos no início do trabalho, a definição de paisagem como aparência (forma) e espaço (forma mais vida) é insuficiente e insatisfatória para tratar as paisagens festivas, que são eminentemente fundamentadas em pensamento mítico e práticas ritualísticas. Tais dimensões, contudo, podem ser recuperadas, na nossa sugestão, pela apreensão da paisagem à maneira de aparição, em que sua tonalidade afetiva nos permite entrar na concretude que têm, na "lógica do espaço mítico", aspectos a princípio meramente espectrais e vê-la não somente como história congelada que participa da história viva, mas como movimento próprio de espacialização dessa história viva. Quem sabe, talvez, com essa proposta, reconheçamos que, parafraseando Shakespeare, "há mais mistérios entre o espaço e paisagem do que possa explicar nossa vã geografia". Afora isto, há que se abrir novos horizontes, além da perspectiva ocularista, notando-se que na paisagem à maneira de aparição sempre haverá algo inapreensível e não é só pela técnica que podemos participar dela. Para concluir, cabem as seguintes palavras de Nietzsche:

"Natureza - fiel e completa?" Como pode chegar a isso?

Quando se conseguiu liquidar a natureza numa imagem?

Mais ínfima parcela do mundo é coisa infinita.

Dele só pinta o que the agrada. E o que the agrada? O que sabe pintar! (s.d., p. 25).

\section{NOTAS}

1Agradeço a João Guilherme Curado, a Tereza Caroline Lobo e a Tito de Oliveira Coelho cujas dissertações de mestrado, que orientei, e teses de doutorado, que ora oriento, auxiliaram-me a refletir sobre 
CASSIRER, Ernst. Antropologia Filosófica. 2. ed., São Paulo: Mestre Jou, 1977 A Filosofia das Formas Simbólicas - A linguagem.

São Paulo: Martins Fontes, 2001

A Filosofia das Formas Simbólicas - O pensamento mítico.

São Paulo: Martins Fontes, 2004

Linguagem e Mito. São Paulo: Perspectiva, 2009.

CLAVAL, Paul. Les points-clefs de la géographie culturelle. Bulletin de l'Association de Géographes Français. Paris, p. 2-10, 1996. A paisagem dos geógrafos. In: CORRÊA, Roberto Lobato ROSENDAHL, Zeny (orgs). Paisagens, textos e Identidade. Rio de Janeiro: EdUERJ, 2004

CORRÊA, Roberto Lobato. Espaço: um conceito-chave da Geografia In: CASTRO, Iná Elias de; GOMES, Paulo César da Costa, CORRÊA, Roberto Lobato. Geografia: Conceitos e Temas. Rio de Janeiro: Bertrand Brasil, 1995, p. 15-48.

ROSENDAHL, Zeny. Apresentando leituras sobre paisagem, tempo e cultura. In: (orgs). Paisagem, Tempo e Cultura. Rio de Janeiro: EdUERJ, 1998.

COSGROVE, Denis. A geografia está em toda parte: cultura e simbolismo nas paisagens humanas. In: CORREA, Roberto Lobato ROSENDAHL, Zeny (orgs). Paisagem, Tempo e Cultura. Rio de Janeiro: EdUERJ, 1998

COSTA, Carmem Lúcia. Cultura, Religiosidade e Comércio na Cidade: a festa em louvor a Nossa Senhora do Rosário em Catalão Goiás. São Paulo: USP, 2010. Tese (Doutorado) - Programa de PósGraduação em Geografia, Universidade do Estado de São Paulo, São Paulo, 2010.

CURADO, João Guilherme. As alterações ocorridas na paisagem por onde passam as procissóes de Pirenópolis - Goiás: 1920 a 2005.
Goiânia: Universidade Federal de Goiás, 2006. Dissertação (Mestrado) - , Universidade Federal de Goiás, Goiânia, 2006

DARDEL, Eric. L'Homme et La Terre. Paris: Presses Uiversitaire de France, 1952.

DUNCAN, James. A paisagem como sistema de criação de signos. In: ROSENDAHL, Zeny; CORREAA, Roberto Lobato (orgs). Paisagens, Textos e Identidade. Rio de Janeiro: EdUERJ, 2004.

HEIDEGGER, Martin. Essais et conferénces. Paris : Gallimard, 1958. Ser e Tempo. 2. ed. Petrópolis: Vozes, 1988, Parte I. . Ser e Tempo. 2. ed. Petrópolis: Vozes, 1990, Parte II.

MAIA, Carlos Eduardo Santos. O retorno para a festa e a transformação mágica do mundo: nos caminhos da emoção. In: ROSENDAHL, Zeny; CORREAA, Roberto Lobato (orgs). Religião, Identidade e Território. Rio de Janeiro: EdUERJ, 2001 ${ }^{\mathrm{a}}$. In: CHAUL, Nasr Fayad, RIBEIRO, Paulo R. (orgs.). Goiás: Identidade, Paisagem e Tradição. Goiânia: Ed. UCG, 2001 b.

Ritual e emoção nas interações espaciais: repensando o espaço sagrado nas festas populares de romarias e folguedos. In: ROSENDAHL, Zeny (org.). Trilhas do Sagrado. Rio de Janeiro: EdUERJ, 2010.

MASSEY, Doreen. Space-time, 'science' and relationship between physical geography and human geography. Trans Inst Br Geogr. n.s 24, p. 261-276, 1999.

NIETZSCHE, F. A Gaia Ciência. Rio de Janeiro: Ediouro, s.d. ROSENDAHL, Zeny. Espaço \& Religião. Rio de Janeiro: UERJ/NEPEC, 1996. Hierópolis: o sagrado e o urbano. Rio de Janeiro: EdUERJ, 1999.

SANTOS, Milton. A Natureza do Espaço: técnica e tempo, razão e emoção. São Paulo: Hucitec, 1996.

Espaço e Método. 5. ed. São Paulo: EdUSP, 2008

SILVA, D. Eduardo Duarte. Passagens (autobiografia). Goiânia: Ed. UCG, 2007.

THOMPSON, John B. A Mídia e a Modernidade. 2. ed. Petrópolis: Vozes, 1998

TUAN, Yi-Fu. Paisagens do Medo. São Paulo: UNESP, 2005.

Festive Landscapes and Interactions-ritualistic in Tradicional Practices of Popular Catholicism

\author{
Abstract: The mythical perception of the landscape festive is the subject of this article, which rescued the investigations of Ernst Cassirer \\ about "the logic of mythical thinking." We begin our approach to defining the landscape as "appearance" that would give an affective


tone. Below, we discuss how the landscape in festivals, the manner of appearance, brings the fervor history, where "entangled states" are promoted by arrests of its mythical-ritual composition.

Keywords: Popular festival. Myth. Landscape. Ritual. 